S. A. PROKOPENKO 1,2, Leading Researcher, Professor, Doctor of Engineering Sciences, sibgp@mail.ru

A. V. DYAGILEVA ${ }^{2}$, Associate Professor, Candidate of Engineering Sciences

N. N. RAVOCHKIN ${ }^{2,3}$, Associate Professor, Candidate of Philosophical Sciences

V. G. SHADRIN ${ }^{4}$, Associate Professor, Candidate of Economic Sciences

${ }^{1}$ VostNII Science Center, Kemerovo, Russia

${ }^{2}$ Kuzbass State Technical University, Kemerovo, Russia

${ }^{3}$ Kuzbass State Agricultural Academy, Kemerovo, Russia

${ }^{4}$ Kemerovo State University, Kemerovo, Russia

\title{
MODELING DEVELOPMENT MECHANISM OF INTELLIGENT INNOVATION POTENTIAL OF MINING ENGINEERS
}

\author{
"Learn from the best. If you want to be a Nobel laureate, \\ you should first become a disciple of a Nobel laureate"
}

Professor V. A. Galkin

\section{Introduction}

The key resource of innovations in the coal industry is engineering personnel and its intelligence, which govern progressive renovation and competitive recovery of the industry [1-3]. Many men of science attempted to grasp and evolve intellectual faculties of human beings [4-9]. Theoreticians and practitioners examine latterly the rates of renovation in coal production $[10,11]$, propose methods to evaluate and stimulate efficiency of human capital in the coal industry $[12,13]$, and develop models and mechanisms of effective innovation activity at coal companies [14, 15]. The intelligent innovation potential of a mining engineer is understood as a level of intelligence and creativity towards innovation in management and technology in combination with energy and will to introduce and practise this potential in mineral mining [16]. This potential comprises two constituents which materialize certain functions of intellect at different stages of innovation activity. These constituents are cognition+creativity (cogni-creative potential) and vision+energy+volition (visen-volitive potential). The cogni-creative potential involves the mind capacities to explore and create, and is applicable at the stage of idea hunt and conversion into innovation in management and technology. The introduction of an innovation into the coal production practice invokes such intellectual assets as vision, energy and volition which make the visen-volitive potential of a mining engineer [17].

Since the 1990s Russian coal industry has been experiencing a decline in innovation activities. From the evidence of the Federal Institute of Industrial Property, only 116 patents for improvements in underground mining and 28 surface miningrelated patents were published between 1993 and 2017 [18]. The average annual number of invention and utility patents in
It is found that present-day mining engineers have a low and disbalanced intelligent innovation potential as compared with the Soviet-era specialists. It is of the current concern to reveal the intelligent innovation potential development mechanism of the engineers in order to stimulate innovative advancement of coal mining companies to keep the achieved level of their competitive abilities. Using the dramatic but successful innovation activity of Mining Engineer $N$. A. Chinakal as an example, the model of step-wise formation of cogni-creative and visenvolitive constituents of the intelligent innovation potential is constructed. The model visualizes the development mechanism and shows a clear skewness of the potential of present mining engineers toward the cogni-creative constituent. The unique level and balance of Chinakal's innovation potential is demonstrated. The logics of engagement of an engineer's brainpower resources and the contents of transition stages in mental work is displayed by the model of orbiting disclosure of a mining engineer's brainpower resources during an innovation process. The model explains how intellect grows and expands while creating and implementing an innovation. Three zones, which are identified in the intelligent innovation potential of an engineer, illustrate the engineer's possible positions and behavior in the course of industrial renovation. The stages of elaboration of an engineer's innovation abilities and the contents of these stages along the way from an idea to an innovation are described. Incipience of special mental forces and accumulation of qualitative changes at the end of the first successful innovation cycle results in formation of the cumulative quality named the inn-experience. Multiplication of success in the next innovation cycles in different geological conditions ensures growth and enrichment of the inn-experience. Together with the accumulated package of put forward but unimplemened inventions, as well as with the experience gained in commissioning of innovations proposed by other inventors, the inn-experience composes the intelligent innovation potential of an engineer. The developed models and algorithm present the mechanism of the intelligent innovation potential which is the high-value intangible assets for the self-improvement of an engineer and for the competitive recovery of a mining company.

Keywords: mine, mining engineer, $N$. A. Chinakal, intelligent innovation potential, novelty, innovation, implementation, cogni-creative potential, visen-volitive potential, mechanism, model, abilities.

DOI: $10.17580 / \mathrm{em} .2021 .01 .18$

the coal science and industry totals only 6 . By experts' estimates, with innovation potential of Soviet-era miners to be assumed as one, their promotional potential is assessable as 0.2-0.3 (Fig. 1).

The actual creative effort of mining engineers - visenvolitive potential - hardly runs up to $30-40 \%$ of the former level, and the visen-volitive potential (promotion and commissioning) strives to zero. Thus and so, the surface and underground mines in Russia should fiercely stimulate the 


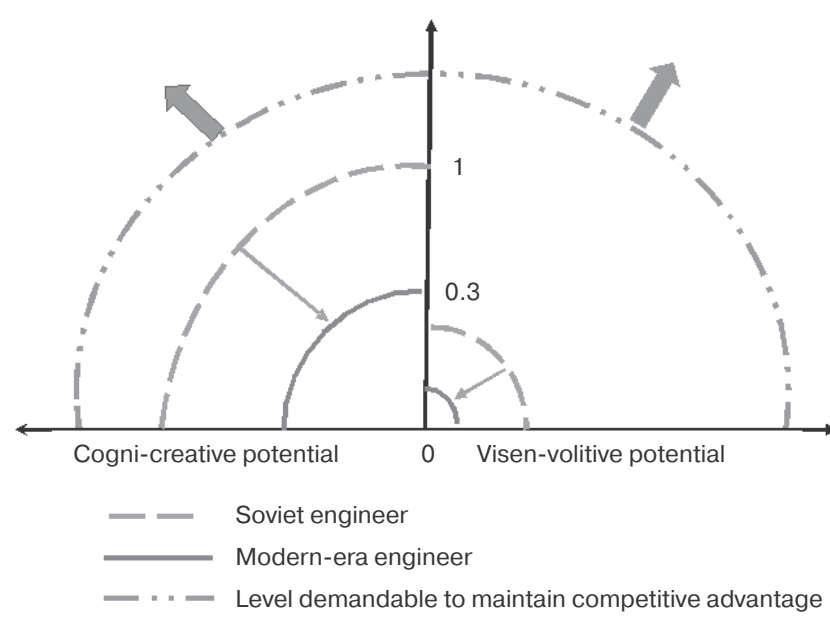

Fig. 1. Cogni-creative and visen-volitive potentials of mining engineers

intelligent innovative potential of engineers and boost the relevant investment $[19,20]$.

The models developed in [17] visualize status of the intelligent innovative potential of mining engineers but offer no disclosure of its mechanism, functions or logical engagement of intellectual assets, their interaction, or results. There is no vision of the scope and quality of mining engineer's intellectual capability accretion and impact on innovation efficiency. These circumstances define the objective of the present research.

\section{Model of increment in intelligent innovative potential of mining engineers}

"When studying science, the examples are more useful than the rules," said Sir Isaac Newton. An example of fruitful innovation activity and balanced development of the intelligent innovative potential is the life and service of a mining engineer and an inventor, professor, Stalin Prize winner and Hero of Socialist Labor N. A. Chinakal (Fig. 2). His idea put forward in 1935 was certified as an invention (Authorship Certificate No. 51298). That invention provided a breakthrough solution for mining of thick and steeply dipping seams.

The pioneer innovation was first neglected by colleagues and management. The idea (phase I in Fig. 2) was thought to be a moonshine and unrealizable fudge. Chinakal went to a lot of trouble to obtain a permit to manufacture and test the first tunneling shield [21]. Having gone through all difficulties, the first tunneling shield in the world was created. The tests were a failure but illustrated operability of the idea (transition to stage 2 in Fig. 2). Again, with all difficulties (often manmade) overcome, the inventor succeeded in his attempts to manufacture another shield. The second test ended with fall over and break-down of the shield, but the creator gained new knowledge and experience (stage 3). The third shield, finally, operated effectively in longwall in Stalin Mine, Stalinugol Trust Company, in October-November 1938, and produced the breakthrough results in terms of coal production output and cost (stage 4 in Fig. 2) [21].

The great paradox was that, despite the best production and economic figures, the new technology arouse no interest of management of the mine, the trust company or

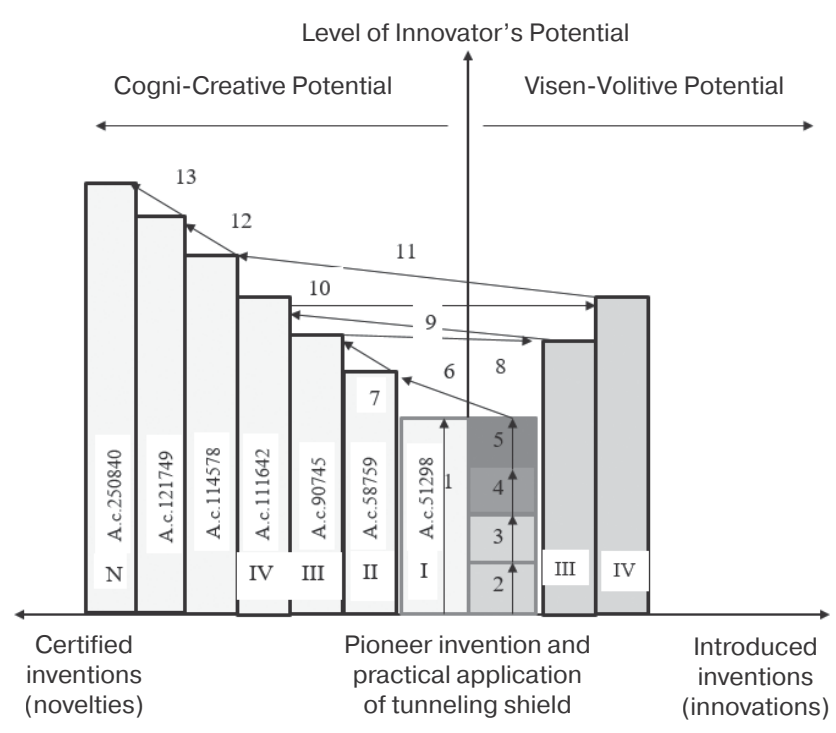

Fig. 2. Model of step-by-step incremental intelligent innovation potential: an example of Mining Engineer N. A. Chinakal:

1 - Pioneer novelty; 2 and 3 - Unsuccessful trial; 4 - Successful tests; 5 - Overcoming of bureaucratic indifference; I, II and III Phases of increment in Int-Inn Potential; 6-13 - transition steps

Kuzbassugol Coal Mining and Processing Plant. The author entered a period 'pushing' the invention into actual application in coal mining (stage 5). Chinakal struggled with the indifference and disinterest of bureaucratic inflexibility. Even his appeal to People's Commissar Kaganovich failed to redress the situation [21]. Only involvement of the Novosibirsk Regional Committee of the Communist Party changed the attitude of senior mining management in Kuzbass. Kuzbassugol Coal Mining and Processing Plant received orders to introduce pilot tunneling shields in operation in some mines, and the novelty materialized as innovation at last. By the mid-1940s, coal mines operated 18 tunneling shields, and shield-equipped longwalls produced $2 \mathrm{Mt}$ of coal in 1941 [22]. The mental power of Chinakal, while being cogni-creative, acquired the visen-volitive ability. Strategic vision, vivid energy and strong will of the inventor took shape of a unique promotional experience, which was gathered and learnt (transitions between stages 2 to 5 ).

As an innovator and being inspired by the acquired experience and results, Chinakal soon put forward another design of a tunneling shield with new components meant to improve its operation. That design obtained Author's Certificate Nos. 58759 and 90745 (transition steps 6 and 7, respectively, in Fig. 2). The knowledge-based creativity and the steps taken up increased the cogni-creative potential of Mining Engineer Chinakal.

The improved design (phase III of the cogni-creative potential) was put into operation in Kalinin Mine, which simplified mining and brought the visen-volitive potential of the inventor to phase III. Further innovations and their commissioning in Kuzbass mines increased step-wise the both constituents of the intelligent innovative potential of the mining engineer. The phases of advance were governed by the farsightedness of innovations. The first idea was a breakthrough 
of the pioneering nature. Paris congress of coal miners in 1956 defined the shield tunneling technology as a technological miracle in the mining science in the 20th century. The technology initiated engineering of advancing roof support in the whole world [22]. Further innovation activity of Chinakal more focused on improvement, which was evident through the higher phases of progression in the intelligent innovative potential.

In all his born days, N. A. Chinakal registered 20 inventions in shield longwall mining of coal seams. The same number of designs and redesigns were put forward without certification. A half of these innovations were tested on a commercial scale, and the most efficient shield designs operated in different mines for many decades. Moreover, the shield tunneling technology was used in ore mining and in coal mining abroad, in Bulgaria, Hungary and China [21]. This is an evidence of the colossal visen-volitive potential Mining Engineer Chinakal cumulated while promoting and adapting his inventions. Quantitatively, his Intelligent Innovative Potential can be given by:

Intelligent Innovative Potential = Cogni-Creative Potential / Visen-Volitive Potential $=40 / 20$.

The model of the intelligent innovative potential describes and visualizes the phase- and step-wise development of its constituents. Modeled suchwise, the same potential of the present-day engineers-inventors looks unbalanced and onesided, with more steps on the left-hand side and without any steps on the right-hand side. There is a clear skew toward the cogni-creative potential. Chinakal raised his innovation potential to the highest level (40 innovations) but balanced with success in commissioning (20 innovations). This is an outstanding standard of innovation activity for engineers both in the USSR and in present-day Russia.

\section{Modeling disclosure of mental power resources of mining engineers}

The above model keeps the contents of transition stages and engagement of intellect resources unclear. We have another model to explain the logic of involvement of mental powers and their functions in transition from the cogni-creative potential to the visen-volitive potential as a mining engineer goes along an innovation cycle (Fig. 3). This is a simplified model of such a sophisticated mechanism as intellect.

When a mining engineer faces a technological challenge (a difficulty, without any obvious way of handling it), the cognitive power actuates (its content is revealed in [16]). Cognition concentrates at the problem and delves into it. This is a reasoned or intuitive uncovering of something which was previously hidden and non-understandable. Mental efforts and time spent for learning, as well as contemplation and intuition enable exposing regular variation of an object (system), its future states and ways to them. Awakening of a shining intelligence transforms into an image of how the problem can be solved Idea 1. Intellect of an innovator gets out of the Seed Potential, beyond the limits of the previous capacities, and bursts into a new orbit of thinking. The range of the brainwork defines the height of the intellectual orbit and the level of newness of the future novelty. It was the extraordinary contemplation ability that permitted N. Chinakal to 'see' the original idea and to bring mentation of his own (and, then, of his colleagues-miners) to a next higher orbit.

Creativity allows intellect to flesh the idea out as a new

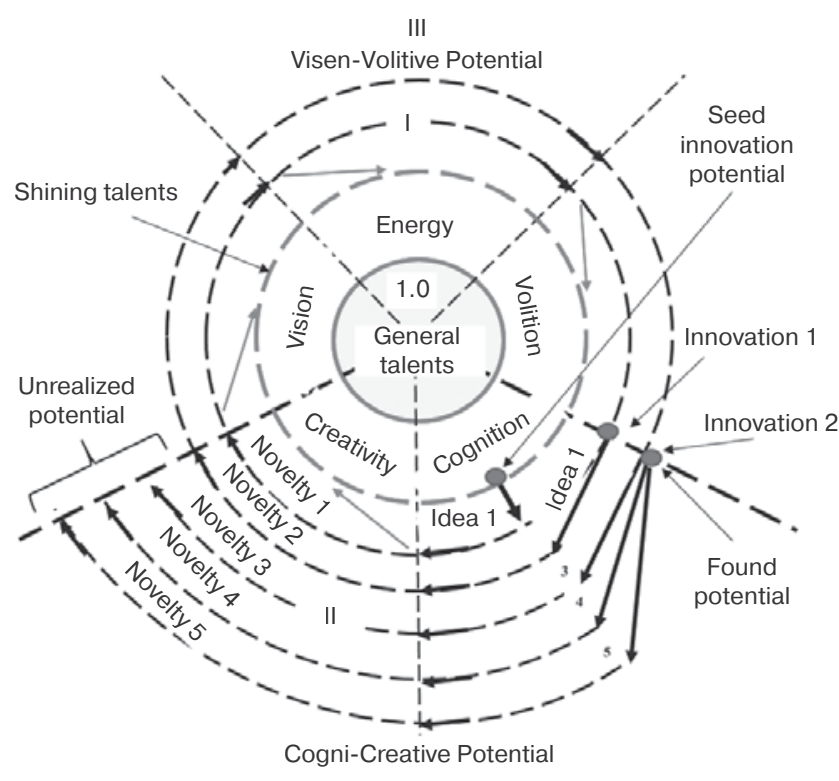

Fig. 3. Model of orbiting disclosure of engineer's intellect resources in innovation process

configuration or composition of a mining object (e.g., a machine), a new combination of its components, or a new logic of mine performance. A mental image of a problem solution comes out and develops. A new orbit of the potential silhouettes and takes shape at the creative stage (black color dashed arrows in Fig. 3). Further steps of solving (drawings, designs, diagrams, prototypes, constructions) lead to absorption of the image and to maturation of a new product (Novelty 1) available for presentation and discussion. From this point on, cognition and creativity (cogni-creative resources) are inplaced by the visen-volitive potential (vision+energy+volition).

An innovator begins to think on the prospects of the creation, its applicability and efficiency in mining practice, and on a testing ground and conditions. This is the actualization of the inventor's ability to handle the solution strategically and tactically, to select a promotion team, and to find resources for embodiment of the novelty. High level of mental vision enables an innovator to reason out and plan the path of the novelty to success.

Implementation of the worked out plan of actions needs sufficient energy to keep on the achieved orbit. The innovator's energy is translated to the team and colleagues and makes them convicted in feasibility and efficiency of the novelty. This energy, when actualized, pushes the novelty toward its implementation and approval.

An engineer should possess and expose the volition resource to overcome obstacles and problems to promote the novelty. Volition as insistence to reach the objective is a necessary condition of effectiveness of a Russian innovator. Chinakal had to back up the first embodiment of his technological breakthrough by his indomitable will and powerful spirit.

The described sequence of disclosure of major intelligence resources at the extraordinary and superlative levels guarantees materialization of breakthrough Idea 1 into Innovation 1. As the innovation cycle is covered, the first orbit closes 
and the innovator's potential comes to next higher level.

Fortification of the milestone achieved and apprehension of the successes enables an engineer to detect shortages and undertake improvements. Idea 2 appears and evolves into a solution and, then, to Novelty 2 (Fig. 3). Brainpower enters a higher orbit of implementation of an engineer's potential and his intellect starts a new innovation cycle. The new cycle launches from the matured level of the Int-Inn Potential, from the position of Innovation 1. The developed level serves the innovation potential of the engineer.

However, not every creator of a breakthrough vision can inventively convert it into an original and effective solution. It often happens that an idea never takes shape for some reasons. The innovation cycle can break while lacking adequate vision, energy and volition of a creator. The potential gets off the reached orbit (red-color meeting arrows in Fig. 3). Only engineers with a mind of the highest rank can materialize the solutions they arrived at, have an effect and meet interests of different participants of innovation. Such engineers start from the Seed Potential level and success in expansion of the potential with every next innovation generated and introduced.

In the model in Fig. 3, after the second novelty is introduced, a few cogni-creative rays emanate from the point of Innovation 2, and generate subsequent and improved Novelties 3, 4 and 5, and the corresponding orbits of the Int-Inn Potential. They increment the cogni-creative potential of an engineer and wait for being implemented in actual coal mining. On the other hand, some novelties may remain undeveloped and make the Unrealized Potential of an engineer.

The model distinguishes between a few qualitatively and functionally different zones in the Int-Inn Potential. Full-Orbit Zone $I$ is formed through disclosure and development of all intellectual resources owing to completion of the idea-innovation cycles. This zone features the balance between the cognicreative and visen-volitive potentials of an engineer. This zone present in the Int-Inn Potential sphere discriminates an innovator and a techno-starter [17].

Generation and patenting of ideas without application in mining form Segment Zone // in the Int-Inn Potential. This is a zone of the unrealized cogni-creative potential of an engineer. It characterizes the innovative capacity. Zone II looks like a segment of incomplete orbits of revealed but unrealized brainpowers of an inventor.

Fruitful participation of a mining engineer in implementation of innovations generated by other specialists enables developing personal visen-volitive potential. Advanced disclosure of vision, energy and volition resources shapes Segment Zone III. This segment is reflective of promotional and commercial capabilities of a person.

Unlike uncommon Full-Orbit Zone I, the two other orbits are segmentary, abridged and prevalent. These zones can be present in the Int-Inn Potential of engineers either individually or in combinations; they impart creators with various capacities and defining promising roles in innovation activities.

Intellect of an innovator is structurally similar to the Solar System. The innovative progression is a stratum which, alongside with other factors, ensures the intellectual and cultural development of a person, etc. The planets in the Solar System are incapable to break away from the Sun's gravity, and, similarly, gravitation of the prevailing perceptions and knowledge restrains flight of ideas of many engineers on lower orbits and keeps them (until accumulation of the breakthrough potential) from escaping beyond the limits of the known. Brains can only 'see' something cardinally new and come to a next orbit of intellect by burst-like overcoming of 'mental gravitation'.

\section{Elaboration of innovation abilities of mining engineer}

Intellectual activity of a mining engineer-innovator according to the models presented above results in elaboration of his special, innovation abilities. They are defined by the specificity of innovation activities in mining, and develop the unique personal potential to change the reality. The stages of elaboration of prime innovation abilities by brainpower during the first and subsequent innovation cycles (orbits of intellect) are described in Fig. 4.

The stage-wise formation of innovation abilities is conditioned by the logic and content of innovation activity of an engineer to evince his competence far and wide at different stages. Springing of special properties of intellect and accumulation of qualitative changes at the end of the first successful cycle (Innovation 1 in Fig. 3) results in generation of the cumulative property named as 'innovative experience' or inn-experience. The inn-experience of an engineer is understood as the deep-felt, experienced and apperceived knowledge, insights and skills to convert new ideas to improved reality. A new quality to appear is restrained by looping at

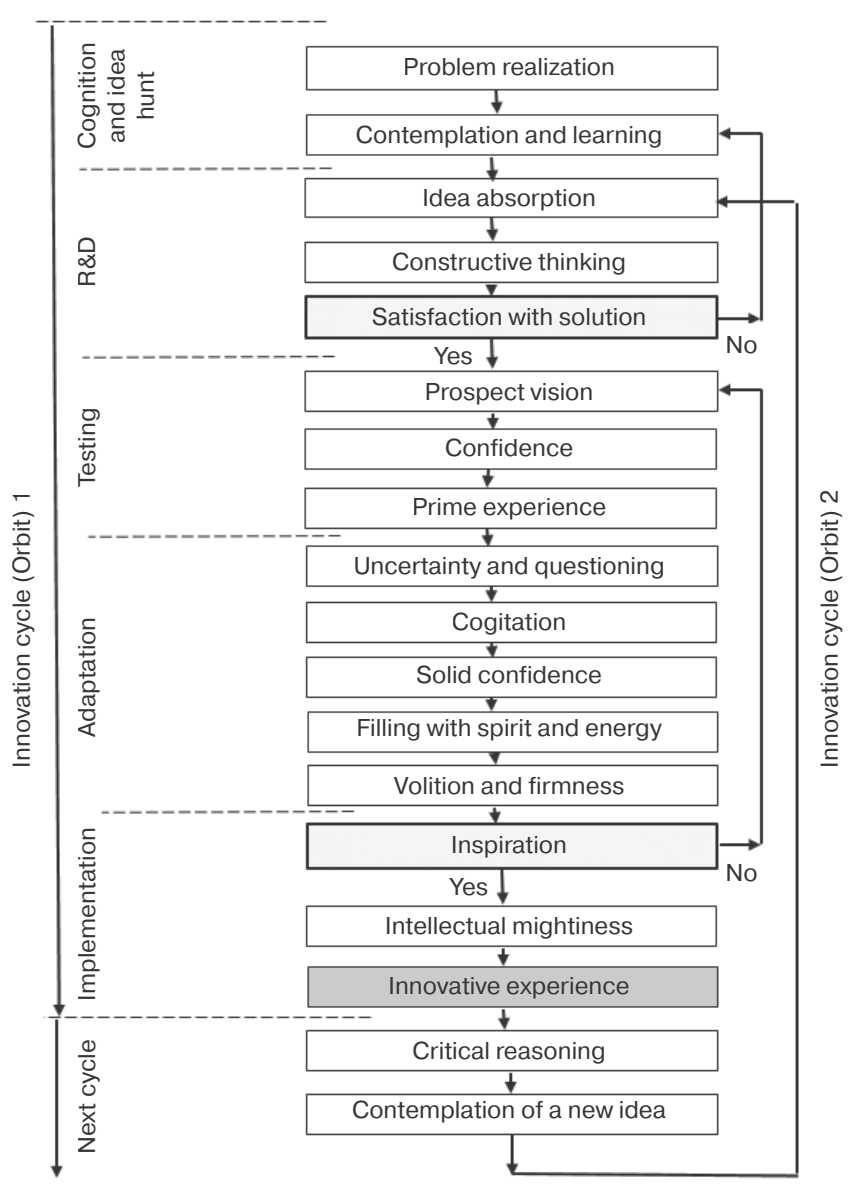

Fig. 4. Algorithm of elaboration of innovation abilities by mining engineer 
intermediate stages due to deficient or incomplete disclosure of intellectual resources. Successful implementation of a novelty and replication of the success in the next innovation cycles ensures expansion and enhancement of the innexperience.

The level of the inn-experience is governed by the number of the personal innovations introduced, their application scale and effect. Together with the accumulated package of proposed but yet unrealized inventions, and with experience gained in commercialization of novelties of others, the inn-experience composes the intelligent innovation potential of an engineer. A wide variety of the innovation abilities developed, their combinability, and the diversity of personal achievements of the participants in innovation activities every time creates a unique intelligent innovation potential which makes the intangibles critical for an engineer as an individual and for a mining company to enhance its competitive advantage.

\section{Conclusions}

1. The intelligent innovation potential of Russian mining engineers is currently on the intolerably low and unbalanced level, which endangers coal mining companies with increasing irrelevance, retardation and competitive incapacity as against foreign coal producers.

2. The model of the intelligent innovation potential of a mining engineer, developed on the ground of N. A. Chinakal's experience, visualizes the steps and levels of the potential's constituents - cogni-creative and visen-volitive. The insight into the content of stepped increment in the innovation potential of an engineer while passing along the way of creativity is offered by the model of orbiting disclosure of brainpower resources. The three zones identified in the IntInn Potential of an engineer explain the behavior of the engineer in the process of renovation. Formation of an engineer's skills is a stage-wise process which cyclically follows the presented algorithm.

3. The models and algorithm expose the mechanism of the intelligent innovation potential of a mining engineer. The research results allow undertaking development of the assessment methods for the Int-Inn Potential, its target expansion and balancing.

References

1. Belkin V. N. Theory of the human capital assets in industry. Yekaterinburg : Institut ekonomiki UrO RAN, 2010. 400 p.

2. Kilin A. B., Azev V. A., Kostarev A. S., Baev I. A., Galkina N. V. et al. Efficient development of a coal production association : Practice and methods. V. B. Artemiev (Ed.). Moscow : Gornaya kniga, 2019. 280 p.

3. Volkov S. A. Stimulation of innovation activities and efficiency of the human capital assets of a mining company : Dissertation of Candidate of Sciences in Economics. Kursk : YUZGU, 2019. $130 \mathrm{p}$.

4. Secchi D., Cowley S. J. Modeling Organizational Cognition: The Case of Impact Factor. Journal of Artificial Societies and Social Simulation. 2018. No. 21(1). DOI: 10.18564/ jasss.3628.
5. Fiorio G. The Ontology of Vision. The Invisible, Consciousness of Living Matter. Frontiers in Psychology. 2016. Vol. 7. DOI: 10.3389/fpsyg.2016.00089. Available at: https://www. frontiersin.org/articles/10.3389/fpsyg.2016.00089/ful (accessed: 27.08.2020).

6. Ribeiro-Soriano D., Berbegal-Mirabent J. Disseminating scientific research: a double-edged sword? Knowledge Management Research \& Practice. 2017. Vol. 15. pp. 380-390.

7. Grohman M. G., Ivcevic Z., Silvia P., Kaufman S. B. The Role of Passion and Persistence in Creativity. Psychology of Aesthetics, Creativity, and the Arts. 2017. Vol. 11(4) pp. 376-385.

8. Gibbons M., Limoges C., Nowotny H., Schwartzman S., Scot P. et al. The new production of knowledge: The dynamics of science and research in contemporary societies. London: SAGE Publications Ltd., 2010. 90 p.

9. Mensky M. B. Intuition and quantum approach to the theory of consciousness. Social Sciences. 2015. Vol. 46(2). pp. 65-77.

10. Artemev V. B., Kilin A. B., Galkin V. A., Makarov A. M. Mining company: the leader and the leadership. GIAB. 2016. Vol. S32. pp. 5-47.

11. Galkin V. A., Osharov A. V., Vorobeva O. V. Personnel of a mining company-key factor of production safety and efficiency enhancement. GIAB. 2015. Vol. S62. pp. 225-237.

12. Korkina T. A. Management of investments in the human capital of coal mines: Goals and means. Ugol. 2009. No. 8. pp. 52-55.

13. Fedorov A. V., Samarin S. V., Kuletskiy V. N., Makarov A. M., Labunskiy L. V. et al. Motivating performance evaluation as a personnel training tool at a coal mine. Ugol. 2011. No. 5. pp. 90-93.

14. Prokopenko S. A., Ludzish V. S., Li A. A. Recycling possibilities for reducing waste from cutters on combined cutter-loaders and road builders. Waste Management \& Research. 2017. Vol. 35(12). pp. 1278-1284. DOI: 10.1177/0734242X17731154.

15. Belkin V. N., Belkina N. A., Antonova O. A. Innovative activity of business managers as a condition for modernization of regional labor potential. Economy of region. 2018. Vol. 14, No. 4. pp. 1327-1340.

16. Prokopenko S. A., Gritskevich T. I., Ravochkin N. N., Dyagileva A. V. The essence of the intelligent and innovation potential of a mining engineer. GIAB. 2020. No. 7. pp. 155-177. DOI: 10.25018/0236-1493-2020-7-0-155-177.

17. Prokopenko S. A., Sementsov V. V. Modeling the intellectual and innovative potential of mining engineers. Ugol. 2020. No. 7. pp. 71-76. DOI: 10.18796/0041-5790-2020-7-71-76.

18. Shaydullina V. K., Pavlov V. P., Sinelnikova V. N., Efimova N. A., Novickaya L. Yu. Legal issues of patenting in the coal industry: challenges of the digital economy, Ugol. 2019. No. 1. pp. 58-62.

19. Yuzhakov V. F. Wanted : Innovators. Ugol Kuzbassa. 2013. No. 6. pp. 42-46.

20. Plakitkina L. S. Innovation stimulation in the coal mining industry in Russia. Gornaya promyshlennost. 2011. No. 3. pp. 4-8.

21. Zvorygin L. V., Kurlenya M. V. Nikolai A. Chinakal. Mining art The life and faith. Novosibirsk: SO RAN, 2001. 184 p.

22. Nikolai A. Chinakal. Novosibirsk Regional Ethnography Portal. Available at: http://kraeved.ngonb.ru/node/5321 (accessed: 27.08.2020.). 